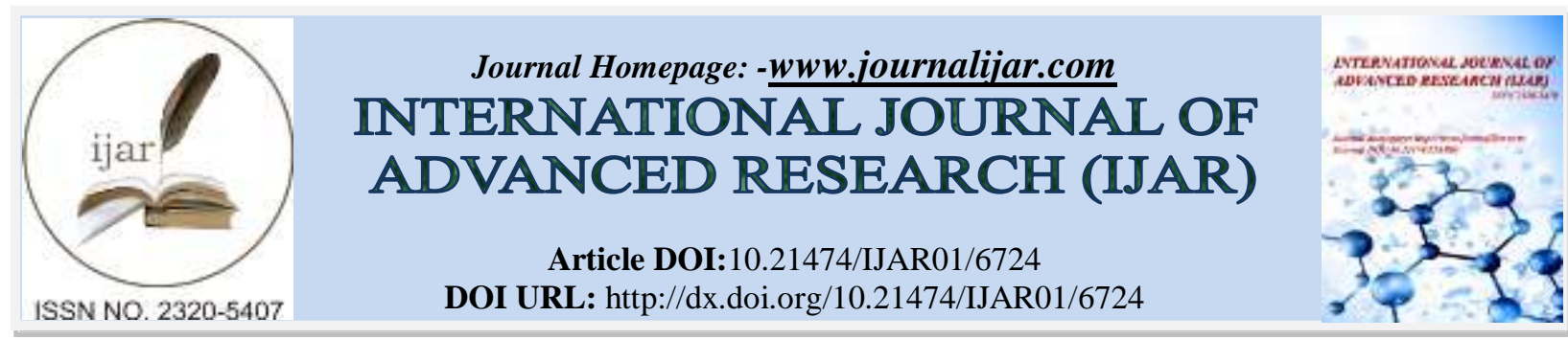

RESEARCH ARTICLE

\title{
AWARENESS OF THE NEED FOR PROFESSIONAL COUNSELLING SERVICES IN MANAGING PSYCHOLOGICAL DISTRESS ASSOCIATED WITH INFERTILITY CHALLENGES: CASE STUDY OF WOMEN OF REPRODUCTIVE AGE IN ASSESSING INFERTILITY TREATMENT AT THE FEDERAL MEDICAL CENTRE LOKOJA.
}

1. Dr. Counselling Psychologist, Federal University Lokoja.

2. Dr Consultant Gynecologist, Federal Medical Centre, Lokoja.

\section{Manuscript Info}

Manuscript History

Received: 12 January 2018

Final Accepted: 14 February 2018

Published: March 2018

\section{Keywords:-}

Counselling, infertility, infertilitychallenges, infertility treatment, psychosocial distress, psychological distress, treatment.

\section{Abstract}

The study adopted descriptive research survey; the target population for the study was women of reproductive age accessing infertility treatment at the Federal Medical Centre, Lokoja-Kogi State, the researchers employed purposive sampling technique, a non-probability sampling technique, to select purposive sample which is a non-representative subset of some larger population, for this study. In-line with ethical consideration, respondents' consents was sought and, respondents were also informed of the confidentiality of the result of the findings, and its use for research purpose only. Forty-eight (48) respondents selected among women accessing infertility treatment at the gynecology clinic on two different clinic days: (Tuesdays' and Thursdays' for the period of eight weeks) participated in the study. The researchers developed the questionnaire tagged: [Need for Professional Counselling Services in Infertility Treatment Questionnaire [NFPCSI ${ }^{2} \mathrm{TQ}$ ] for the study. To establish the reliability of the questionnaire test-retest was employed, the initial draft of the questionnaire was administered on ten (10) nonparticipated samples twice at the interval of two weeks, result of Pearson Moment product correlation-co-efficiency yielded ' $r$ ' $=0.72$. A senior lecturer from the department of English-Language, Federal University Lokoja assisted for language editing, a Consultant Obstetrician and Gynecologist validated the contents and face validity of the instrument. For statistical analysis, independent sample t-test to test for testing hypotheses formulated for the study. Findings from the study revealed that presently there is no formal professional counselling services put in place in infertility treatment, and respondents were aware of the need for professional counselling services in infertility, so as to adequately manage psychological distress associated with infertility among women with infertility challenges. Recommendations made include the need for inclusion of formal professional counselling services in infertility treatment or at least, physicians namely Obstetrician and Gynecologists should always make referral of women with infertility challenges to professional counselling psychologists. 


\section{Introduction:-}

Infertility is the inability of a person, animal or plant to reproduce by natural means. It is usually not the natural state of a healthy adult, in humans, infertility is the inability to become pregnant or carry a pregnancy to full term. Infertility is a medical and social condition that can cause considerable social, emotional and psychological distress; infertility is medically defined as a lack of conception following at least one year of unprotected sexual intercourse (WHO, 2009). It is estimated that one in six couples experience infertility at some point in their lives, and the World Health Organization has called for the recognition of infertility as a public health issue worldwide, McArthur, (2007). Infertility and its treatment can have a considerable impact on a person's quality of life and infertility problems can be among the most upsetting experiences in people's lives. Infertility has been ranked as one of the great stressors in life, comparable to divorce and death in the family (Holter, Anderheim, Bergh \& Möller (2006). Burns, 2007; Peterson, Goad \& Feingold, (2007), have highlighted the similarities between coming to terms with infertility and the grieving process. (Woods, Olshansky \&Draye (1991); Wirtberg, Möller, Hogström, Tronstad \& Lalos (2007); McCarthy, 2008) pointed out that, unlike grieving because of bereavement, the grieving caused by infertility does not follow a sequential pattern, but it is recurrent and triggered by life events, the birth of other people's children and grandchildren, as well as the cyclic nature of the menstrual cycle.Burns, (2007) writes on an overview of the range of psychological, emotional, social and practical difficulties that women affected by fertility problems often encounter as presented in the table1:

\begin{tabular}{|l|l|}
\hline Emotional effects & $\begin{array}{l}\text { - Grieving and depression; - Anger and frustration; - Guilt;- Shock and denial;- Anxiety, } \\
\text { feelings of alienation from the 'fertile world'; a sense of social stigma, difficulty of dealing } \\
\text { with meaning of infertility in own life, immersion in the treatment process, stressful nature } \\
\text { of the treatment process itself, strained relationships with health care providers (Greil, 1997) }\end{array}$ \\
\hline Loss of control & $\begin{array}{l}\text { - Loss of control over activities, body, emotions; - Inability to predict and plan future, } \\
\text { - Loss of health;- Loss of security (about a predictable future) }\end{array}$ \\
\hline $\begin{array}{l}\text { Effects on self- } \\
\text { esteem, identity \& } \\
\text { beliefs }\end{array}$ & $\begin{array}{l}\text { - Loss of self-esteem and self-confidence, feelings of inadequacy; - Identity problems or } \\
\text { shifts, loss of status or prestige; - Changes in world views }\end{array}$ \\
\hline Social effects & $\begin{array}{l}\text { - Effects on marital interactions and satisfaction (positive and negative) } \\
\text { - Effects on sexual functioning } \\
\text { - Different social network interactions, changes in relationships with network members, } \\
\text { loneliness, embarrassment, feelings of defectiveness and reduced competence, especially for } \\
\text { women perceived lack of status and ambiguity }\end{array}$ \\
\hline $\begin{array}{l}\text { Loss of a (potential) } \\
\text { relationship }\end{array}$ & $\begin{array}{l}\text { - Loss of fantasy or hope of fulfilling an important fantasy, loss of relationship with spouse, } \\
\text { loss of relationship with the social network, loss of health and sexual pleasure, loss of status } \\
\text { and/or prestige loss of self-esteem, - Loss of something or someone of great symbolic value, } \\
\text { loss of confidence and/or control, loss of security, loss of hope } \\
\text { - Loss of future and past in one person }\end{array}$ \\
\hline
\end{tabular}

Table 1:- Observed psychological effects of infertility [Adapted from (Burns, 2007)]

Schmidt, Christensen, Holstein (2005), reported that infertility treatment can extract a heavy psychological toll for which patients are often unprepared and that fertility patients have expressed a need for more emotional advice and support, and for professional psychosocial services. The consequences of infertility are manifold and can include societal repercussions and personal suffering. In many cultures, inability to conceive bears a stigma. In closed social groups, a degree of rejection (or a sense of being rejected by the couple) could cause considerable anxiety and disappointment. The desire to have children is universal and that most couples have life plans that include children, in addition societal expectations also play a role in the desire to procreate, and where childbearing is a societal and cultural imperative, unintentionally childless couples feel even more isolated by their situation. Parenthood is perceived in most cultures as a central developmental milestone towards adulthood (Baor \& Blickstein, 2005). Infertility, therefore, can cause a major disruption in people's lives because it interferes with the established and desired life course. Infertility can cause considerable distress. Often cited consequences of infertility are: depression, anxiety, sexual anxiety/difficulty, relationship problems with partner, family and friends, and an increased sense of self-blame and guilt (Monach, 2005; Klock, 2008). Feelings of anger, bitterness, guilt, denial and isolation have also been found among and women experiencing this problem. In some cases women, often blame past behaviours, such 
as sexual indiscretions, sexually transmitted infections or abortions, for their infertility, which further compounding their stress and anxiety (Cosineau \& Domar, 2007; Klock, 2008).

\section{Need for the study:-}

Despite infertility being a relatively common problem, people affected by it often believe it to be rare and find themselves feeling isolated from family and friends. An increase in public awareness and information is therefore crucial in order for couples/women who are the main recipients of interventions for infertility due to their biological role in pregnancy and childbirth to feel supported during their difficulties. Reducing the stigma and secrecy that surrounds fertility problems will enable couples to feel less isolated in their plight, and better able to discuss their problems with both their social network and with health professionals. Infertility is a complex state. There is a danger that the emotional impact of infertility is neglected and that the condition is reduced only to be medical one. The provision of psychosocial support/ the need for infertility counselling has been neglected, patients have relied primarily on their spouse and family when distressed, rather than on more formal support resources. Reasons preventing patients from counselling uptake have varied, with less distressed patients using their existing resources, and more distressed patients failing to initiate contact with the counselling service because of practical concerns such as not knowing how to do so and cost implications. The counselling service plays a major complementary role in providing holistic patient-centered care. In view of these psychological distresses associated with infertility challenges /treatment the researchers decided to investigate the issue on perceptions on the need for professional counselling services in infertility treatment.

\section{The need for infertility counselling services:-}

Infertility counselling deals primarily with the psychosocial impact of infertility, in terms of social life, treatment and the aftermath of both successful and unsuccessful treatment. Infertility counselling deals with implications, that is helping patients to understand and contemplate their treatment options and the short and long-term implications of treatment. It is important for health care professional s to be sensitive and to understand how infertility influences a woman's life, how she response to subsequent life events, and the meaning that she attaches to life stage transitions as she grows up and is in contact with peer group and grandparents. Infertility counselling guidelines

1. Professional in infertility treatment should understand that infertility consultations differ from other medical consultations in obstetrics and gyneacology.

2. The treatment and many interventions may not be successful and which could lead to depression, desperation and emotional problems

3. The infertility consultations differ from other disease consultations in the following manners: i) Main focus of consultation is just an unfulfilled wish to have a child and not a specific disease, also infertile women have mixed feelings of hope and loss in facing fertility treatment; ii) the wish involves a third party who is not even born at the present time.

4. Counselors need to be knowledgeable about medical and psychosocial aspects of infertility and fertility treatment; Gender differences in emotional reactions to infertility and infertility treatment should be noteded.

5. Infertility counselors need to recognize the stressful nature of fertility treatment, prepare infertile clients for intense emotional reactions, and facilitate effective coping for all possible treatment outcomes.

\section{Types of infertility counseling:-}

Within the context of this research the following three types of counselling are identified in addition to the necessary medical procedures, one should also focus on the patients psychosocial and emotional needs by:

\section{Implications counseling:-}

According to Crawshaw, Hunt, Monach, Pike, Wilde (2012), the Human Fertilization and Embryology Authority (HFEA) states: counselling should be offered when an individual or couple seek treatment that will create embryos in vitro or to store their gametes or embryos; seek treatment with donated gametes or embryos; this type of decision making requires implications counselling which includes, informed consent and highlights the consequences of treatment options and decisions, for everyone involved in the process.

\section{Support counseling:-}

In this area of counselling, the counsellor offers emotional support before, during or after treatment, particularly to those experiencing stress, ambivalence or distress.ESHRE (2012) states, the provision of emotional support should be part of any patient-centered care and treatment that focus specifically on the coping resources that may help in managing stressful situations. Also, HFEA (2012) provides guidelines on psychological interventions to support 
patients during the decision-making process and throughout treatment, helping patients to make adjustments to their lives.

\section{Therapeutic counseling:-}

Therapeutic counselling typically tends to be a natural progression from support counselling. According to HEFA (2012), the content of therapeutic support includes reflection on the individual's/ couple's problem, acceptance of their situation, the meaning and impact of infertility and treatment, and discussion about alternative lifestyles and assistance in developing positive and purposeful roles for the future and addressing specific issues such as sexual, marital and other potential interpersonal problems.

\section{Research Hypotheses:-}

Null Hypothesis One: 'There is no significant difference in the means score of women's perception on the need for professional counselling as part of infertility treatment on the basis of types of infertility challenges (primary/ secondary').

Null Hypothesis Two: 'There is no significant difference in the means score of women's perception on the need for professional counselling as part of infertility treatment on the basis of length of years of infertility treatment'.

Null Hypothesis Three: 'There is no significant difference in the means score of women's perception on the need for professional counselling as part of infertility treatment on the basis of level of education'.

Null Hypothesis Four: 'There is no significant difference in the means score of women's perception on the need for professional counselling services in managing psychosocial aspect of infertility'.

\section{Assumptions for the study:-}

The following assumptions were made for the study:

1. That psychosocial distress such as depression, anxiety, guilt, self-blame, hopelessness, helplessness, are associated with infertility challenges;

2. That appropriate counselling services is required /needed to help patients in managing such challenges;

3. That women accessing infertility treatment may not be aware of the need for counselling services in the treatment of infertility;

4. That women accessing infertility treatment may not be aware of the role for counselling services in the treatment of infertility.

\section{Methodand Materials:-}

Descriptive research survey was adopted for the study; the target population for the study was women of reproductive age accessing infertility treatment at the Federal Medical Centre, Lokoja-Kogi State, the researchers employed purposive sampling technique, a non-probability sampling technique, due to the nature of the population for the study (namely women with infertility challenges), to select purposive sample which is a non-representative subset of some larger population, for this study. In-line with ethical consideration, respondents' consents was sought by asking them to fill and sign consent form, respondents were also informed of the confidentiality of the result of the findings, and its use for research purpose only. Forty-eight (48) respondents selected among women accessing infertility treatment at the gynecology clinic on two different clinic days: (Tuesdays' and Thursdays' for the period of eight weeks) participated in the study. The researchers personally administered the questionnaire to the respondents on their clinic days.

\section{Results of Findings:-}

Hull Hypothesis One: 'there is no significant difference in the means score of women's perception on the need for professional counselling as part of infertility treatment on the basis of types of infertility challenges (primary/ secondary)".

To test for this hypothesis the researchers asked: "Are you aware of the need for professional counselling services as part of infertility treatment?" 
Table 31.1:- Independent sample t-test on: "significant difference in the means score of women's perception on the need for professional counselling as part of infertility treatment on the basis of types of infertility challenges (primary/ secondary)"

\begin{tabular}{|c|c|c|c|c|c|c|c|c|}
\hline Item & Response & $\mathrm{N}$ & $\bar{x}$ & SD & $\mathrm{t}$-cal & $\mathrm{t}$-cri & Df & Remark* \\
\hline $\begin{array}{l}\text { Are you aware of the need } \\
\text { for professional } \\
\text { counselling services as part } \\
\text { of infertility treatment? }\end{array}$ & Agreed & 12 & 1.75 & 0.43 & 27.70 & 2.01 & 47 & \\
\hline & Disagree & 36 & & & & & & \\
\hline
\end{tabular}

$* \mathrm{P}=$ Significant $(\mathrm{p}<0.05)$

Result of data analysis in table 3.1:1 showed a calculated t-value of 27.70; and the t-tab of 2.01 at degree of freedom 47 , at 0.05 alpha level of significant; calculated $t$-value of 27.70 greater than the $t$-tab of 2.01; since the calculated tvalue of 27.70 greater than the t-tab of 2.01, the null hypothesis one is rejected, this showed that significant difference exist in the means score of women's perception on the need for professional counselling as part of infertility treatment on the basis of types of infertility challenges (primary/ secondary)"

Null Hypothesis Two: "there is no significant difference in the means score of women's perception on the need for professional counselling as part of infertility treatment on the basis of length of years of infertility treatment".

To test for this hypothesis the researchers asked: "You think length of years of infertility treatment affect your awareness of the need for professional counselling services as part of infertility treatment?"

Table 31.2:- Independent sample t-test on: significant difference in the means score of women's perception on the need for professional counselling as part of infertility treatment on the basis of length of years of infertility treatment

\begin{tabular}{|l|l|l|l|l|l|l|l|l|}
\hline Item & Response & $\mathrm{N}$ & $\overline{\mathrm{x}}$ & $\mathrm{SD}$ & $\mathrm{t}$-cal & $\mathrm{t}$-cri & $\mathrm{DF}$ & Remark* \\
\hline $\begin{array}{l}\text { You think length of years of infertility } \\
\text { treatment affect your awareness of the } \\
\text { need for professional counselling } \\
\text { services as part of infertility treatment? }\end{array}$ & Agreed & 27 & & & & & & \\
\hline & Disagree & 21 & 1.43 & 0.50 & 19.86 & 2.01 & 47 & \\
\hline
\end{tabular}

$* \mathrm{P}=$ Significant $(\mathrm{p}<0.05)$

Result of data analysis in table 3.1:2 showed a calculated t-value of 19.86 and the t-tab of 2.01; at degree of freedom 47 , at 0.05 alpha level of significant; calculated t-value of 19.86 greater than the t-tab of 2.01; since the calculated tvalue of 19.86 is greater than the t-tab of 2.01; the null hypothesis two is rejected, this showed that significant difference exists in the means score of women's perception on the need for professional counselling as part of infertility treatment on the basis of length of years of infertility treatment.

Null Hypothesis Three: "There is no significant difference in the means score of women's perception on the need for professional counselling as part of infertility treatment on the basis of level of education".

To test this hypothesis, the researchers asked "you think that education level affect women's perception on the need for professional counselling as part of infertility treatment"

Table 31.3:- Independent sample t-test on: no significant difference in the means score of women's perception on the need for professional counselling as part of infertility treatment on the basis of level of education".

\begin{tabular}{|c|c|c|c|c|c|c|c|c|}
\hline Item & Response & $\mathrm{N}$ & $\bar{x}$ & SD & $\mathrm{t}$-cal & t-cri & Df & Remark* \\
\hline $\begin{array}{l}\text { asked "you think that education } \\
\text { level affect women's perception on } \\
\text { the need for professional } \\
\text { counselling as part of infertility } \\
\text { treatment }\end{array}$ & Agreed & 31 & 1.33 & 0.48 & 19.41 & 2.01 & 47 & \\
\hline & Disagree & 17 & & & & & & \\
\hline
\end{tabular}

$* \mathrm{P}=$ Significant $(\mathrm{p}<0.05)$ 
Result of data analysis in table 3.1:3 showed a calculated t-value of 19.41and the t-tab of 2.01; at degree of freedom 47, at 0.05 alpha level of significant; calculated t-value of 19.41 greater than the t-tab of 2.01; since the calculated tvalue of 19.41 is greater than the t-tab of 2.01, the null hypothesis three is rejected, this showed that there is significant difference in the means score of women's perception on the need for professional counselling as part of infertility treatment on the basis of level of education.

Null Hypotheses four $\left(4 \mathrm{H}_{0}\right)$ : “There is no significant difference in the means score of women's perception on the need for professional counselling services in managing psychosocial aspect of infertility.

To test this hypothesis the researchers asked: "Would you rather suggest that professional counselling services be part of infertility treatment in the hospital'?

Table 3:1.4:- Independent sample t-test on: "significant difference in the means score of women's perception on the need for professional counselling services in managing psychosocial aspect of infertility.

\begin{tabular}{|l|l|l|l|l|l|l|l|l|}
\hline Item & Response & $\mathrm{N}$ & $\mathrm{x}$ & $\mathrm{SD}$ & $\mathrm{t}$-cal & t-cri & Df & Remark* \\
\hline $\begin{array}{l}\text { "Would you rather suggest } \\
\text { that }\end{array}$ & Agreed & 36 & 1.25 & 0.43 & 19.79 & 2.01 & 47 & \\
$\begin{array}{l}\text { counselling services be part } \\
\text { of infertility treatment in } \\
\text { the hospital"? }\end{array}$ & & & & & & & & \\
\hline & Disagree & 12 & & & & & & \\
\hline
\end{tabular}

$* \mathrm{P}=$ Significant $(\mathrm{p}<0.05)$

Result of data analysis in table 3.1:4 showed a calculated t-value of 19.79 and the t-tab of 2.01, at degree of freedom 47, at 0.05alpha level of significant; calculated t-value of 19.79 greater than the t-tab of 2.01; since the calculated tvalue of 19.79 is greater than the t-tab of 2.01,the null hypothesis three is rejected, this showed that significant difference exists in the means score of women's perception on the need for professional counselling services in managing psychosocial aspect of infertility.

\section{Findings from the study:-}

Results of this study showed that

1. significant difference exist in the means score of women's perception on the need for professional counselling as part of infertility treatment on the basis of types of infertility challenges (primary/ secondary)" this shows that women with primary infertility and those with secondary infertility are different in their perception on the need for professional counselling as part of infertility treatment,

2. significant difference exists in the means score of women's perception on the need for professional counselling as part of infertility treatment on the basis of length of years of infertility treatment, this implies that length of years of infertility treatment affect respondents' perception on the need for professional counselling as part of infertility treatment.

3. There is significant difference in the means score of women's perception on the need for professional counselling as part of infertility treatment on the basis of level of education,this shows that level of education affect respondents' perception on the need for professional counselling as part of infertility treatment,

4. Significant difference exists in the means score of women's perception on the need for professional counselling services in managing psychosocial aspect of infertility, this shows that respondents were different in their perception on the need for professional counselling services in managing psychosocial aspect of infertility.

\section{Discussion of Findings:-}

Results of findings from testing the hypotheses showed that there is the need for formal professional counselling services currently in infertility treatment unlike the experience in the UK, reports from National Institute for Health and Care Excellence (NICE, 2013), that infertility counselling is a specialty that combines the fields of reproductive health psychology with reproductive medicine, and NICE, (2013), reported that in the UK, a number of professional bodies have individually established guidelines which influence the provision and delivery of the counselling service as part of infertility treatment. Findings from hypothesis four of this study agrees with Crawshaw , Hunt, Monach , Pike, Wilde, (2013). Crawshaw et al.(2013) reported that: "as a result of the ever advancing medical and treatment knowledge and practices in the field of infertility, British Infertility Counselling Association [BICA] was founded in 1988 to represent the interests, views and needs of members actively involved in counselling people with fertility issues and of other professionals involved in related research. BICA is an independent body which 'aims to 
encourage and facilitate its members to provide the highest standards of counselling support to people affected by fertility issues', and that there is an increasing awareness and growing consensus that it needs to be a mental health professional and that services are integral to the optimum care of the patient. Boivin, Bunting, Collins \& Nygren (2007), in a related study reported that psychosocial intervention was effective in improving the well-being of infertile couples who participated in a group counselling interventions which emphasized education and skill training such as relaxation counselling techniques.

Report of study by Wischmann, 2008; reported that counselling and support group were found to be to be efficient psychosocial interventions, and pointed that the beneficial aspect of support group stems from participants' being able to share experiences and information related to infertility as well as ideas for coping. Fekkes,. Buitendijk, Verrips, Braat,. Brewaeys, Dolfing, Kortman, Leerentveld \& Macklon (2003), reported that review of best practice in psychosocial support for fertility patients have suggested that counselling should take place before infertility treatment to provide patients with infertility challenges with the opportunities to learn the skills to cope with the infertility and the associated medical procedures, and that it is important to ensure that psychological support is available throughout treatment, especially at those times that have been identifies as most stressful such as time of egg retrieval or time of waiting for pregnancy; and that psychotherapeutic interventions should continue after unsuccessful treatment while patients come to terms with involuntary childlessness. Report of study by Wischmann, 2008; reported that counselling and support group were found to be to be efficient psychosocial interventions, and pointed that the beneficial aspect of support group stems from participants' being able to share experiences and information related to infertility as well as ideas for coping.

\section{Recommendations:-}

The following recommendations are made

1. There is the need for inclusion of formal professional counselling services in infertility treatment procedure of women with infertility problem.

2. Physicians namely Obstetrician and Gynecologists should always make referral of women with infertility challenges to professional counselling psychologists.

3. Women with infertility problem should make themselves available for counselling services where this is available, in addition to religious counselling.

4. All (hospitals and clinics) private as well as (government owned) should put in place functional health counselling departments that will adequately take care of emotional needs of women with infertility problem so as to help in managing psychological distress associated with infertility diagnosis.

\section{Acknowledgements:-}

The researchers are grateful to management of Federal Medical Centre Lokoja for the permission to conduct the study, as well as women of reproductive age accessing infertility treatment at the gynecology clinic of the health institution, whose consent were sought before voluntarily participated in the study.

\section{References:-}

1. Baor, L. and I. Blickstein (2005). "The journey from infertility to parenting multiples: a dream come true?" International Journal of Fertility 50 (3): 129-134.

2. Boivin, J., L. Bunting, J. A. Collins and K. G. Nygren (2007). "International estimates of infertility prevalence and treatment-seeking: potential need and demand for infertility medical care." Human Reproduction 22 (6): 1506-1512.

3. Boivin, J., L. Bunting, J. A. Collins and K. G. Nygren (2007). "International estimates of infertility prevalence and treatment-seeking: potential need and demand for infertility medical care." Human Reproduction 22 (6): 1506-1512.

4. Burns, L. H. (2007). "Psychiatric effects of infertility and infertility treatments." Psychiatric Clinics of North America 30: 689-716.

5. Cosineau, T. M. \& A. M. Domar (2007). "Psychological impact of infertility." Best Practice Research in Clinical Obstetrics and Gynaecology 21 (2): 293-308. doi: 10.1016/j.bpobgyn.2006.12.003. PMID 17241818

6. Fekkes, M., S. E. Buitendijk, G. H. W. Verrips, D. D. M. Braat, A. M. A. Brewaeys, J. G. Dolfing, M. Kortman, R. A. Leerentveld and N. S. Macklon (2003). "Health-related quality of life in relation to gender and age in couples planning IVF treatment." Human Reproduction 18 (7): 1536-1543. 
7. Gnoth, C., E. Godehardt, P. Frank-Herrmann, K. Friol, J. Tigges and G. Freundl (2005). "Definition and prevalence of subfertility and infertility." Human Reproduction 20 (5): 1144-1147.

8. Greil, A. L. (1997). Infertility and psychological distress: A critical review of the literature. Social Science Medicine, 45, 1679-1704

9. HFEA (2008), Infertility: The HFEA guide. London: Human Fertilization and Embryology Authority. http://www.hfea.gov.uk/docs/Guide2.pdf

10. Holter, H., L. Anderheim, C. Bergh and A. Möller (2006). "First IVF treatment - short term impact on psychological well-being and the marital relationship." Human Reproduction 21 (12): 3295-3302.

11. Klock, S. (2008) 'Psychological Issues Related to Infertility'. http://www.glowm.com/?p= glowm. cml/ section view\&articleid $=412$

12. McCarthy, P. (2008). "Women's lived experiences of infertility after unsuccessful medical intervention." Journal of Midwifery and Women's Health 53 (4): 319-324.

13. Monach, J. (2005). Psychological aspects of infertility. Bristol: British Fertility Society. http://www.british fertilitysociety.org.uk/public/factsheets/docs/BFS-psychosocial\%20aspects\%20of\%20infertility.pdf

14. National Institute for Health and Care Excellence (NICE, 2013) Assessment and Treatment for People with Fertility Problems. CG156. London. [https://www.nice. org.uk/guidance/ cg156].

15. Peterson, B. D., L. Gold and T. Feingold (2007). "The experience and influence of infertility: considerations for couple counsellors." The Family Journal 15 (3): 251-257.

16. Schmidt L, Christensen U, Holstein BE (Apr 2005). "The social epidemiology of coping with infertility". Hum. Reprod. 20 (4): 1044-52. doi:10.1093/humrep/deh687. PMID 15608029.

17. WHO (2013) Fertility: Assessment and Treatment for People with Fertility Problems. London:Retrieved 201306-17.

18. Wirtberg, I., A. Möller, L. Hogström, S.-E. Tronstad and A. Lalos (2007). "Life 20 years after unsuccessful infertility treatment "Human Reproduction 22 (2): 598-604.

19. Wischmann, T. (2008). "Implications of psychosocial support in infertility - a critical appraisal." Journal of Psychosomatic Obstetrics and Gynecology 29 (2): 83-90.

20. Woods, N. F., E. Olshansky and M. A. Draye (1991). "Infertility: women's experiences." Health Care for Women International 12: 179-190. 